\title{
A Study into the Reading Construct: Validating Item Types of Reading Tests
}

\author{
WADA Tomoko \\ Graduate School at Tokyo University of Foreign Studies
}

\section{INTRODUCTION}

In the field of English Language Teaching, whether it is in a pedagogical environment or in a research environment, many situations exist where some sort of language ability assessment has to be undertaken. However, the skills that are required in certain language activities, such as reading, are often not directly observable. Therefore, one of the difficulties in making a test that measures such language abilities is keeping its construct validity high, or in other words, making a test that measures what it purports to measure. For a precise measurement of language abilities, it is crucial that a clear picture of reading construct is revealed. The present study was undertaken in order to seek a way of how reading construct could be described. The study puts its focus on reading sections from two standardized English proficiency tests and attempts to identify how the test items can be categorized from the perspective of what sort of reading process they elicit.

\section{REVIEW OF LITERATURE}

\subsection{Divisibility of reading ability}

Whether and how reading ability is broken down into component skills is an issue which has long been argued by many researchers. In an attempt to support the "unitary" approach to reading ability, Alderson and Lukmani (1989) was one of the first studies to claim that it is not possible to differentiate between reading and test taking processes, with Alderson (1990), a replication of Alderson and Lukmani (1989) with a more carefully constructed test, supporting their claim. Rost (1993), although this was a study on $\mathrm{Ll}$ reading, agreed with the unitary approach to reading ability, suggesting that the variance in reading ability could be attributed to one dimensional 'general reading comprehension'. Although the unitary approach to reading ability had established a strong position in reading research, some studies attacked the unitary approach: Lumley (1993), with empirical support from his study, being one of them. He replicated Alderson (1990) and concluded that his data suggested the multidimensionality in test takers' reading ability.

The solution to the debate on the validity of trying to identify reading test taking processes in a reading test is supplied first by Lumley (1995) and later by Negishi (1996). Although Lumley does not use the term 'test specifications' explicitly, Negishi (1996) takes the point and suggests that the list that Lumley (1993) actually used in his research should be regarded as a set of test specifications rather than a collection of reading subskills. Indeed, the test that was used in Lumley (1993) was designed principally to provide 'diagnostic' information about students' language proficiency, and Lumley himself comments in Lumley (1995) that in test-taking (as opposed to real life), the way in which an item is constituted, or the task it imposes on the test-taker, may be integral to the way in which it is answered. What caused the debate was the lack of 
recognition that reading ability is unitary in psychometric sense and multidimensional in psychological sense, a notion suggested in Henning (1992) and Shizuka (1998).

Bernhardt (1999) takes the same approach and suggests the unidimensionality of the reading process while taking the interactiveness of the reading process components into account. However, she also emphasizes the necessity to "conceptualize how a particular question is supposed to capture an interactive dimension of second language reading." (p. 8) The reading process can be described as an interaction of reading process components. Therefore, it is not possible to measure the ability to use one reading component discretely, and this allows us only to have a unitary measurement of reading ability (e.g., whether one succeeds in answering an item). However, at the same time, there is no doubt whatsoever that reading ability is a combination of skills in multiple cognitive activities (Shizuka 1998), and once considered from the perspective of construct validation, what is essential to the research of reading construct seems to be to come up with a way to categorize these interactions of reading components so that the test constructors would have a way to describe the reading construct underlying the test construction.

\subsection{A two-dimensional approach to the reading construct}

In defining the reading construct, many teachers and researchers have long employed the concept of skills-set, or taxonomies, for its usefulness (Urquhart and Weir 1998:90). However, these taxonomies, as well as the studies that had employed these taxonomies, have not escaped criticisms (e.g. Alderson 1990) for their lack of preciseness and discreteness in defining the taxonomies.

Blais and Laurier (1995) claims that reading subskills would be better described if they are thought to line up in a continuum, rather than as a taxonomy, to be inclusively enough or to escape conceptual overlaps. The factor analytic study of reading ability in Negishi (1996) also claims that "subtraits are much smaller in number than reading skills as conventionally listed in the literature" (p.131). Negishi (1997) continues on this line of approach and suggests that reading construct on which to base test specifications be defined in terms of two axes on a plane. The concept of "two-dimensional approach" suggested in Negishi (1997: 49) is described in Figure 1.

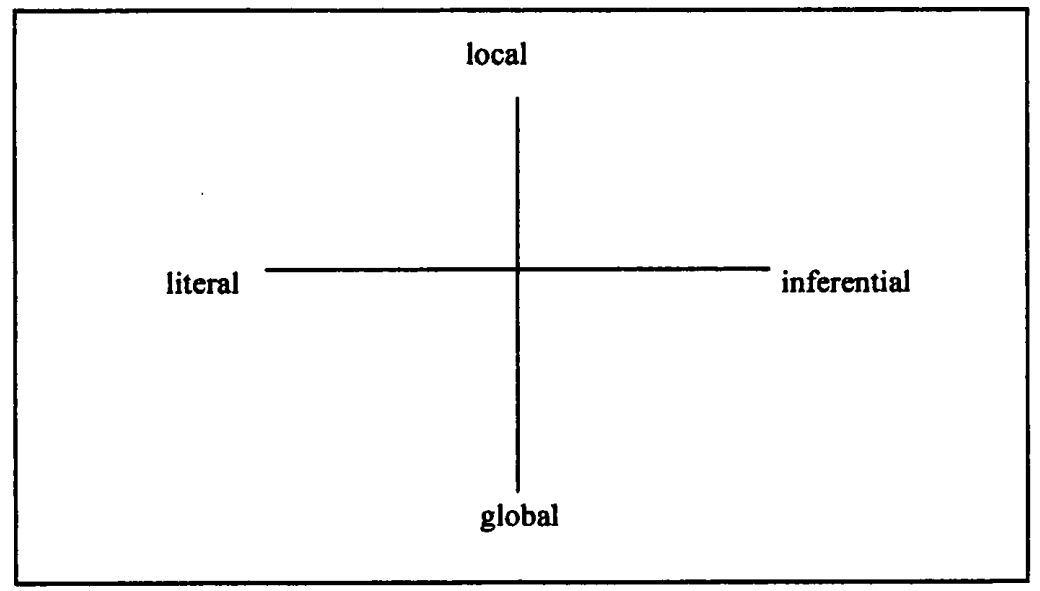

Figure 1. The reading subskill model suggested in Negishi (1997) 
The vertical axis indicates the quantity of information needed to answer the test item. Negishi (1997) terms this as local-global axis on which "local" end indicates extracting micropropositional ideas and "global" end indicates extracting macropropositional ideas from the text. The horizontal axis indicates the quality of information needed to answer the test item. Negishi (1997) terms this as literal-inferential axis on which "literal" end indicates constructing the meaning by "reading the lines" type of reading and "inferential" end indicates constructing the meaning by "reading between the lines" type of reading.

Shizuka (1999) also employs a two-dimensional approach, which is similar to Negishi (1997)'s approach, in categorizing reading test taking processes. He had three subcategories in the dimension of related linguistic unit size and three in the dimension of cognitive depth, suggesting, in total, nine categories in which reading subskills could be allotted. However, when the three raters in his study categorized what reading subskills the test items were testing, they showed little consistency in their judgement. This could suggest that nine categories underlying two dimensions was too many to guarantee their "comprehensiveness" in describing reading test taking process.

Nevertheless, the two-dimensional approach to describing reading ability employed both in Negishi (1997) and Shizuka (1999) seem reasonable when the definition of reading by Bemhardt (1999) along with the definitions by some other researchers (e.g., Gernsbacher 1990; Grabe 1999) is revisited. For example, Gernsbacher (1990) suggested a formula which describes reading ability, " $\mathrm{D} \times \mathrm{C}=\mathrm{R}$ " (decoding $\times$ comprehension $=$ reading), and it assumed two dimensions in reading ability.

The two-dimensional approach suggested by Negishi (1997) encompasses many of reading definitions and takes them further in order to describe them as reading construct. The present author has decided to employ it in considering the dimensions that describe what sort of reading process reading test items elicit in TOEFL and TOEIC reading sections. In employing this model, the present author has refined the descriptions of "local-global" axis and "literal-inferential" axis to avoid any confusion. On the "local-global" axis, the amount of information the test items ask in order to come up with the correct option is indicated, and on "literal-inferential" axis, the depth of the comprehension required to come up with the correct option is indicated.

\section{METHODOLOGY}

\subsection{Research Questions}

This research focuses on the following three questions:

1) Is ability in L2 reading comprehension, as measured by performance of senior high school students in Japan on $\mathrm{L} 2$ reading comprehension tests, multi-dimensional?

2) What are the factors that constitute the dimensions of reading test taking processes as measured by performance of senior high school students in Japan on L2 reading comprehension tests?

3) Would the factors that are extracted from the reading tests used in the study of research question 2 be extracted in the same way when the same test items that bore high factor loadings in 
previous tests are put together as a different test and given to a different set of students with similar English ability?

\subsection{Subjects}

Samples of around 140 (137 for the Trial 1, 138 for the Trial 2, 146 for the Trial 3,159 for the Final Trial) third year senior high school students were taken. The majority of students had five years of English education under Monbusho curriculum in English as a foreign language environment. Some students were returnees who had studied English abroad, but the variation of the number of years they had spent and the intensity of how much English they had learned abroad were too great that it was not possible to come up with any criterion for omitting the scores to ensure generalizability. Although sampling was accomplished because the present author was responsible for their English classes, it would seem reasonable to assume that the sample well represents the population of Japanese senior high school. Students were allotted to classes so that equal amount of variation in their academic levels are ensured in each class. The number of students varied for each trial, because some students were absent for some of the trials.

\subsection{Procedures}

There are two parts to this research: Study 1 and Study 2. Study 1 was undertaken to answer Research Question 1 and 2, and Study 2 was undertaken to answer Research Question 3.

\subsubsection{Experiment and materials (Study 1)}

The purpose of Study 1 was to see if reading ability elicited by reading test items could be identified as something multidimensional, and, if it could be, how. This was examined by using full-information factor analyses of how students tackle items in different reading tests.

The test instruments employed in Study $1^{1}$ are as follows:

Trial 1: 18 items selected from 'Practice Exercise' (Part VII: reading comprehension) and 'Full-length Practice Test' (Part VII: reading comprehension) sections in TOEIC Official Test-Preparation Guide (2000) and 4 items selected from 'Practice Questions A' (Section 3: Reading Comprehension) in TOEFL Test Preparation Kit Workbook (1998) (22 iteris in total)

Trial 2: 22 items selected from 'Ptactice Questions A' (Section 3: Reading Comprehension) and 'Practice Test B' (Section 3: Reading Comprehension) in TOEFL Test Preparation Kit Workbook (1998)

Trial 3: 22 items selected from 'Practice Test A' (Section 3: Reading Comprehension),

'Practice Test B' (Section 3: Reading Comprehension), and 'Practice Test C'

(Section 3: Reading Comprehension) in TOEFL Practice Tests Volume 2 (1997)

The present author, with advice from her colleagues, selected the items intuitively because some of the items assumed contexts that were unfamiliar to the subjects and because some passages seemed too difficult for the subjects. Nevertheless, the items were selected so that they all held the same difficulty and so that different topics/contents of passages were included. Furthermore, descriptive statistics were investigated to ensure that there is no great difference in 
items and in test difficulty among the three trials, and also, to ensure validity and reliability of the three trials. At this point, in selecting the items, no attention was paid to the reading test taking processes that test items were eliciting.

Trial 1, Trial 2, and Trial 3 were administered respectively with one class period each in interval. In the interval period, an ordinary English class ("Reading") was conducted. This was for a pedagogical reason that administering three full-period test consecutively would demotivate students both in participating in class and in cooperating with the research. The testees were given 50 minutes to complete each test and were asked to provide their answers on mark-sheets, and these marks-sheets were scored electrically on a mark-sheet scanner.

\subsubsection{Experiment and materials (Study 2)}

The purpose of Study 2 was to validate the three types of reading ('local literal comprehension', 'local inferential comprehension', and 'global inferential comprehension') that were identified to constitute reading ability via the performance of senior high school students in Japan on Study 1 of the present research. To validate the factors that were extracted from the reading tests used in the study of Research Question 2, those test items that bear high factor loadings were selected and given to a different set of students with similar English ability. If the same factors as the ones observed in the study of research question 2 are extracted after an factor analysis, it is highly possible that those factors are the ones that constitute the dimensions of different reading test taking processes.

The test instrument employed in Study 2 (Final trial) ${ }^{2}$ was a collection of items from Trial 1 , Trial 2, and Trial 3 of Study 1. The present author consulted the results from factor analyses in Study 1 (Trial 1,2, and 3) and picked the items that bore high factor loadings on one of three factors. She further selected the items so that an equal number of items were chosen from the three reading test taking processes, the three trials, and the text/content types. Some items had to be changed with new items, which affected the balance of items considered above, because attention was paid so that items that shared the same passage were chosen. Theoretically, it is not appropriate to have too many items that share the same passage in a test that measure certain reading subskills because testees' context knowledge could contaminate the theasurement of subskills. However, in the present study, this could not be avoided in order to reduce the amount of reading the testees have to do and fit the itertls into a 50-minute test.

Table 1. A priori category of test items in Final Trial

\begin{tabular}{|c|c|c|c|c|c|c|c|c|}
\hline text \# & $\begin{array}{c}\text { I } \\
\text { TOEIC }\end{array}$ & $\begin{array}{c}\text { II } \\
\text { TOEIC }\end{array}$ & $\begin{array}{c}\text { III } \\
\text { TOEIC }\end{array}$ & $\begin{array}{c}\text { IV } \\
\text { TOEFL }\end{array}$ & $\begin{array}{c}\text { V } \\
\text { TOEFL }\end{array}$ & $\begin{array}{c}\text { VI } \\
\text { TOEFL }\end{array}$ & $\begin{array}{c}\text { VII } \\
\text { TOEFL }\end{array}$ & $\begin{array}{c}\text { VIII } \\
\text { TOEFL }\end{array}$ \\
\hline text & $\begin{array}{c}\text { Business } \\
\text { letter: road }\end{array}$ & $\begin{array}{c}\text { Announce- } \\
\text { ment on trip } \\
\text { cancellation } \\
\text { s }\end{array}$ & $\begin{array}{c}\text { Business } \\
\text { letter: } \\
\text { declining an } \\
\text { job offer }\end{array}$ & $\begin{array}{c}\text { Native } \\
\text { Americans } \\
\text { way of lie }\end{array}$ & $\begin{array}{c}\text { Biography } \\
\text { of a female } \\
\text { writer }\end{array}$ & $\begin{array}{c}\text { Developme } \\
\text { nt of food } \\
\text { preserving } \\
\text { techniques }\end{array}$ & $\begin{array}{c}\text { Developme } \\
\text { nt of } \\
\text { lighting } \\
\text { technigues }\end{array}$ & $\begin{array}{c}\text { Styles of } \\
\text { film making }\end{array}$ \\
\hline a. loc/lit & & 4 & 7 & 11 & & 17 & 22 \\
\hline b. loc/inf & 1 & 2,3 & 5 & 8 & 10,12 & & $16,18,19$ & 21 \\
\hline c. glo/inf & & & 6 & 9 & & $13,14,15$ & & 20 \\
\hline
\end{tabular}


After the item-selection process, Final Trial consisted of five items intended to measure local literal comprehension, eleven items intended to measure local inferential comprehension, and six items intended to measure global inferential comprehension (22 items in total). Please refer to Table 1 for an a priori category of test items in Final Trial.

\subsubsection{Data analyses}

Both in Study 1 and Study 2, the statistical information obtained were:

1. Analysis of test item data: means standard deviations, KR20 of each trial and items along with facility values, discrimination indice, and point biserial of each item.

2. Factor analyses for the collected data in order to see if the testees' performance on each trial reveal a unitary trait or multiple subskills. The nature of the factors generated will also be consulted.

As it is explained in Negishi (1996: 87), there are some problems related to the use of traditional factor analysis methods with binary data (i.e., items scored right or wrong). The classical factor analysis model does not fit the dichotomously scored test items because the model is based on continuous data (Negishi 1996: 87-88), and he suggests 'full-information factor analysis' to be used in such cases. Bock (1984), cited in Negishi (1996: 89), defines full-information factor analysis as a marginal maximum likelihood procedure that provides a test of the dimensionality of the underlying ability continuum and, when multidimensionality is identified, it indicates how the items may be partitioned into unidimensional sets. The present study employed "full-information factor analysis" performed by TESTFACT 2 (Scientific Software International).

\section{RESULTS AND DISCUSSION}

\subsection{Study 1}

\subsubsection{Descriptive statistics}

Descriptive statistics for each test are shown in Table 2.

Table 2. Descriptive statistics and reliability coefficients of each trial

\begin{tabular}{|c|c|c|c|c|c|c|}
\hline Trial \# & \# of testees & Mean & S.D. & Minimum & Maximum & KK20 \\
\hline Trial 1 & 137 & 9.1 & 3.5 & 2 & 19 & 0.625 \\
\hline Trial 2 & 138 & 12.7 & 4.1 & 3 & 22 & 0.739 \\
\hline Trial 3 & 146 & 11.7 & 4.2 & 3 & 21 & 0.738 \\
\hline
\end{tabular}

Overall, the present author found no problematic results in the descriptive statistics. The KR 20 may seem too low, considering that TOEIC or TOEFL administered in the formal situation usually bears KR 20 of higher than 0.9 . This could indicate the true underlying multidimensionality of the ability being tested. However, it could also be because the tests employed in the present study only partially used the original test and had only a limited number of items. Therefore, it was decided that the reliability of 0.625 for Trial $1,0.739$ for Trial 2, and 0.738 for Trial 3 would be accepted for the time being.

The facility values and point biserials of individual items in all three trials were also 
examined. However, the present author found no items that are too problematic for the present study and decided to include all items in the factor analytic study.

\subsubsection{Factor analysis}

The full-information factor analysis was applied to all the items in Trial 1,2, and 3. Tables of factor loadings are presented in Table 3. In the factor analytic study of the three trials, the oblique (PROMAX) analysis was thought to be preferable for its interpretability and because some factors (literal and inferential factors and local and global factors, if they exist) might possess correlational relationship with each other. The present author consulted her colleagues, friends who are graduate students specializing in English Language Teaching or Second Language Acquisition, and her supervisor for the interpretations of factors and reading test taking processes assumed from the result of factor analyses to ensure objectivity.

Three-factor solutions were adopted for all the trials because of their interpretabilities, and this indicates that reading ability measured via Trial 1,2 , and 3 are all multidimensional. One thing noticed is that the text (context) characteristics did not affect the extraction of factors. Items from different prompts had significant loadings on the same factors, and the loadings of the items that came from the same prompt varied greatly for each factor. The loadings are generally quite high, and there seems to be a cut point at .4 where the items can be judged if they load heavily on certain factors.

Table 3. Full-information factor analysis of items from each trial

\begin{tabular}{|r|r|r|r|l|l|l|r|}
\hline Trial 1 & & & & & & & \\
\hline promax & & & & & & \\
\hline & 1 & 2 & 3 & & & \\
\hline 11 & .749 & -.038 & .091 & & & \\
\hline 12 & .680 & .095 & -.106 & & & & \\
\hline 5 & .521 & .215 & -.533 & & & \\
\hline 15 & .514 & -.096 & .035 & & & \\
\hline 14 & .482 & .121 & -.087 & & & \\
\hline 20 & .459 & -.164 & .290 & & & \\
\hline 2 & .454 & .185 & .056 & & & \\
\hline 8 & .435 & -.018 & .078 & & & & \\
\hline 4 & .391 & .308 & .119 & & & & \\
\hline 7 & .352 & .258 & .019 & & & & \\
\hline 16 & .287 & .020 & .026 & & & & \\
\hline 6 & .230 & .845 & .070 & & & & \\
\hline 19 & .204 & -.071 & -.073 & & & & \\
\hline 21 & .164 & -.301 & -.043 & & & & \\
\hline 1 & .143 & .382 & .141 & & & & \\
\hline 10 & .113 & .061 & .026 & & & & \\
\hline 13 & .102 & .105 & .387 & & & & \\
\hline 17 & .045 & .668 & .576 & & correlations & \\
\hline 18 & .034 & .190 & .623 & & 1 & 2 & \\
\hline 9 & -.027 & .439 & -.314 & 1 & 1 & & \\
\hline 3 & -.028 & .153 & .027 & 2 & .235 & 1 & \\
\hline 22 & -.399 & .371 & .271 & 3 & .233 & -.067 & \\
\hline
\end{tabular}




\begin{tabular}{|c|c|c|c|c|c|c|c|}
\hline Trial 2 & & & & & & & \\
\hline promax & 1 & 2 & 3 & & & & \\
\hline 21 & .952 & -.186 & .037 & & & & \\
\hline 22 & .621 & -.088 & .132 & & & & \\
\hline 7 & .307 & .356 & -.072 & & & & \\
\hline 4 & .293 & -.063 & .158 & & & & \\
\hline 20 & .286 & .182 & -.304 & & & & \\
\hline 15 & .272 & -.118 & .330 & & & & \\
\hline 17 & .256 & .244 & .379 & & & & \\
\hline 12 & .232 & .156 & .072 & & & & \\
\hline 19 & .161 & .297 & .093 & & & & \\
\hline 10 &.$\overline{144}$ & .204 & .790 & & & & \\
\hline 6 & .122 & .134 & .298 & & & & \\
\hline 5 & .084 & .561 & .269 & & & & \\
\hline 1 & .084 & .307 & .217 & & & & \\
\hline 9 & .071 & -.037 & .453 & & & & \\
\hline 8 & .061 & .432 & .051 & & & & \\
\hline 18 & .011 & .246 & -.002 & & & & \\
\hline 16 & -.015 & .396 & .064 & & & & \\
\hline 3 & -.028 & .095 & .568 & & corr & lations & \\
\hline 13 & -.069 & .653 & -.268 & & 1 & 2 & 3 \\
\hline 2 & -.146 & -.110 & .583 & 1 & 1 & & \\
\hline 14 & -.223 & .762 & .047 & 2 & .484 & 1 & \\
\hline 11 & -.471 & .584 & .300 & 3 & .418 & .307 & 1 \\
\hline
\end{tabular}

\begin{tabular}{|r|r|r|r|l|l|l|r|}
\hline Trial3 & & & & & & \\
\hline promax & 1 & 2 & 3 & & & \\
\hline 16 & .784 & .111 & .145 & & & \\
\hline 1 & .703 & -.034 & .319 & & & \\
\hline 8 & .682 & -.045 & -.305 & & & \\
\hline 19 & .630 & -.147 & -.094 & & & \\
\hline 10 & .623 & -.259 & -.187 & & & \\
\hline 4 & .593 & -.020 & .111 & & & \\
\hline 11 & .531 & .255 & .050 & & & \\
\hline 12 & .478 & -.020 & -.146 & & & \\
\hline 9 & .474 & .012 & -.019 & & & \\
\hline 13 & .448 & -.395 & .194 & & & \\
\hline 21 & .442 & .021 & .071 & & & \\
\hline 2 & .431 & .226 & -.157 & & & \\
\hline 6 & .413 & .113 & -.435 & & & \\
\hline 20 & .410 & .257 & -.040 & & & \\
\hline 17 & .394 & .592 & .086 & & & \\
\hline 7 & .361 & -.004 & -.125 & & & & \\
\hline 15 & .280 & .132 & .403 & & & \\
\hline 5 & .273 & -.052 & -.041 & & \multicolumn{2}{|c|}{ correlations } \\
\hline 22 & .251 & -.070 & -.361 & & 1 & 2 & 3 \\
\hline 14 & .243 & -.594 & -.014 & 1 & 1 & & \\
\hline 3 & .060 & .038 & .595 & 2 & .114 & \multicolumn{1}{|c|}{1} & \\
\hline 18 & .050 & .197 & -.260 & 3 & -.181 & -.186 & 1 \\
\hline
\end{tabular}

In Trial 1, from comparison of the factor loadings with actual test questions, it can be said that the items that ask for answers that could be obtained by paraphrasing or making inferences 
from a small amount of information integration (i.e., a word or a phrase) given in the passage loaded heavily on the first factor. There were many items of this type in Trial 1 , and in fact, half the number of items in Trial 1 loaded heavily on it. The items that ask for answers that could be obtained by directly returning to a small amount of information in the passage or by returning to an exact wording of the correct answer in the passage loaded heavily on the second factor. The items that loaded heavily on the third factor asked for answers that could be obtained by making inferences from the information given in the passage as a whole.

In Trial 2, from the comparison of factor loadings with actual test questions, it can be said that the items that ask for answers that could be obtained by making inferences from or referring to the information given in the passage as a whole loaded heavily on the first factor. There were not so many items of this type in Trial 2. They are only items 21 and 22, and their factor loadings for the first factor ( 0.952 for item 21 and 0.621 for item 22) are quite distinct from others, for example, the third highest item $7(0.307)$. This could be either because the characteristics of passage overrode the subskills identified by the items or because the subskills identified were very distinct for these two items. However, loadings on the other two factors show that factor generation was not influenced by the passage characteristics. Furthermore, when the actual items are consulted, it was observed that these two items asked for the same type of reading. For example, item 21 had a question, 'Which of the following types of food preservation was NOT mentioned in the passage?' To answer this question, the testees have to look all over the passage, integrating quite a large amount of information, to infer whether the options given in the items are introduced as a way to preserve food. The same thing could be said about item 22, in which testees have to refer to the whole of the passage to find the statement that is supported by the passage.

The number of items that loaded heavily on the other two factors was balanced, and the loadings were quite high, too. The items that ask for answers that could be obtained by paraphrasing or making inferences from the small information-integration given in the passage loaded heavily on the second factor. Item 14, which asks the testees to identify where in the passage the author describe the benefits people derive from plants, can be answered with little information-integration because where to look is given by the options. The item can be also aniswered by inferring the author's aim in listing how plants have played a role in people's lives. Furthermore, item 13 is another prototypical local inferential item that could be found in all three trials, inferring the meaning of a word or a phrase.

The items that loaded heavily on thie third factor ask for answers that could be obtained by directly returning to the words or phrases (a small information-integration) in the passage. Item 10, which loaded the heaviest on the third factor, along with item 3 , which loaded the second heaviest, asked for the answers that could be reached by returning to (almost matching) a word or some words in the passage with the options.

In Trial 3, most of the items loaded heavily on the first factor. This could mean that, although a three-factor solution was adopted, the reading ability measured via Trial 3 was indeed unitary. However, from inspecting the actual test questions for the four items (Items 1, 8, 19, and 10) that loaded quite heavily on the first factor, it was evident that these items asked for answers 
that could be obtained by paraphrasing or referring to the small information-integration given in the passage. Item 17, which was judged to have loaded heavily on the second factor, asks for the main idea of the passage that could be obtained by making inferences from the information given in the passage as a whole. The same could be said for item 14. From these analyses, it can be said that the second factor is 'global inferential' factor. Items which loaded heavily on the third factor ask for answers that could be obtained directly from the passage or those of which exact wording of the correct answer is in the passage. Therefore, the third factor was a 'local literal' comprehension factor.

\subsubsection{Discussion of Study 1}

Although there were some differences among the trials in the extent of how much, the reading ability measured via the performance of Japanese senior high school students on the three trials was perceived to be multidimensional. This answers Research Question 1 of the present study. It was true in Trial 3 that many of the items loaded heavily on the first factor, suggesting the possibility of the reading ability being unitary. However, on the other hand, it was also true in Trial 2 that clear distinctions of factors could be found. The number of items that loaded heavily on each of three factors were balanced to form three distinct reading test taking processes measure via testees' performance on Trial 2. Therefore, although more investigation in this aspect seems necessary, it would be valid to assume the multidimensionality of the reading ability.

With regard to Research Question 2 of the present study, three similar reading test taking processes identified and interpreted in the three trials are:

a. The ability to return to a small information-integration and understand what is directly and exactly stated in the passage (local literal comprehension of the text)

b. The ability to refer to a small information-integration and understand what is implicitly stated by making inferences from the words and phrases in the passage (local inferential comprehension of the text)

c. The ability to refer to a large information-integration and understand the passage globally, to come up with macropropositional idea of the text (global inferential comprehension of the text)

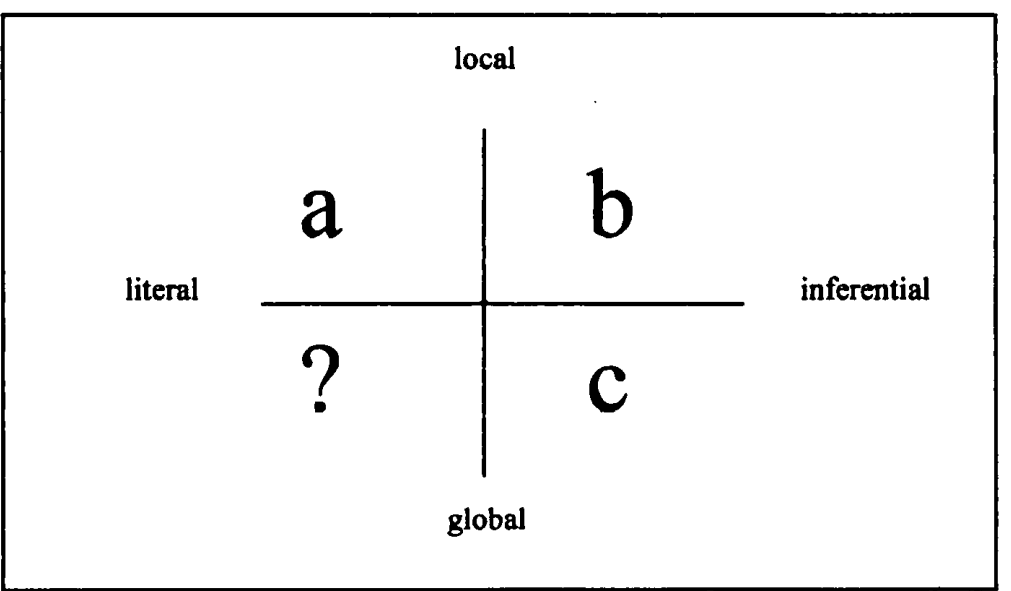

Figure 2. The reading subskill model after factor analytic study of three trials in Study 1 
These categories of reading test taking processes are similar to those suggested by the students' performance on TOEFL reading test in Study Two of Negishi (1996): 'literal comprehension factor', 'local inference factor', and 'global comprehension factor'. In regard with the 'two-dimensional' plane defined by 'local-global' axis and 'literal-inferential' axis, which was suggested in section 2.2. in the present study, a dimension of 'global literal comprehension' could not be identified. Therefore, whether reading ability could be illustrated in the two-dimensional approach, as indicated in Figure 2, could not be verified. Three things are possible to account for this: 1) The present reading construct, which is described by 'two-dimensional' plane, is not valid, and some other way to describe reading construct should be sought, 2) No items that elicit the reading test taking process identified by the dimension of 'global literal comprehension' were present in the three trials, or 3) Although there were items that elicit 'global literal comprehension' in the three trials, students did not do the type of reading intended by such items.

An example of 'global literal comprehension' would be 'scanning'. Scanning is the type of reading in which one goes through the whole of given text quickly to spot an exact word or phrase that is asked for in the question (Urquhart and Weir, 1998). According to Urquhart and Weir (1998), if the item were to measure the ability to scan, it has to be timed because, given time longer than appropriate to scan, it is possible that the testees reach answers via types of reading other than the one intended. In other words, when abundant time is given to work on a 'speed' test, the test is no longer measuring 'speed' factor of testees' reading ability. This might be a possibility in the present study. Because the testees were given sufficient time to complete the test, the items that purport to elicit 'global literal comprehension' was answered as 'power' items, eliciting types of reading other than intended. For example, item 21 and 22 of Trial 2 was perceived to be global inferential type in the factor analytic study of Study 1 . However, these question types ('Which of the following types of $\mathrm{X}$ was NOT mentioned in the passage?' or 'Which of the following statements is supported by the passage?') changes in the type of reading they elicit when the time constraints are given. Under certain time pressures, the testees would not have time to stop and 'make inferences' as they did in the present study. If time constraints are put upon these trials, items 21 and 22, along with other 'perceived-to-be-inferential' items, may be identified as a 'global literal' or 'local literal' type. In a way, this idea synthesizes possibility 2) and 3) above. However, the present condition does not reveal any solution, and more empirical investigation is necessary to provide any definite explanatibhs.

Lastly, some of the items in Study 1, which were categorized into one of the three reading test taking processes identified in the present section, do not conform with the intuitive categorization of reading test taking processes they are thought to elicit. This is not to say that the interpretation of the factors made in the present study is unreliable. Because the testees use different strategies to read the same passage, whether they are compensatory or relevant in its terms, the categorization by factor analysis sometimes did not match intuitions. However, in the present research, especially in selecting items to be used in Study 2, the present author avoided employing 
intuitive (and therefore, subjective) categorization and used the reading test taking process identified in Study 1 even when she did not agree with it.

\subsection{Study 2}

In the factor analytic study of Study 1 , it was validated that the reading ability measured via the performance of senior high school students in Japan on the three trials is multidimensional. Furthermore, the interpretations of the factor loadings suggested that the three reading test taking processes identified via the present instrumentations are 'local literal comprehension', 'local inferential comprehension', and 'global inferential comprehension'. However, because these reading test taking processes were based on the 'interpretations' of factor loadings, a further empirical attempt to validate the interpretation is necessary. Furthermore, because the distinction between the factors was not so clear in some cases in Study 1, an attempt should be made to further investigate the dimensionality of reading ability. If the reading test taking processes that were identified across different trials (Trial 1, 2, and 3) are valid, the same sort of factors (hence, reading test taking processes) would be generated again when the items from these trials that loaded heavily on one of three factors are put together as one test (Final Trial). The study was undertaken in Study 2. (See Table 1 for the categories of 22 items included in Final Trial.)

\subsubsection{Descriptive statistics}

Table 4 shows the descriptive statistics and reliability coefficient of Final Trial. Overall, the present author found no problematic results in the descriptive statistics. The mean of 11.9 with the standard deviation of 4.7 seems appropriate and bears little difference in the test difficulty from the three trials in Study 1. The minimum score of three and the maximum score of 21 is appropriate, and most of all, the KR 20 of 0.801 indicates that, although there were many constraints in selecting the items for Final Trial, the test as a whole came out with no problems that give threat to the reliability of the study.

Table 4. Descriptive statistics and reliability coefficient of Final Trial

\begin{tabular}{|c|c|c|c|c|c|}
\hline \# of testees & Mean & S.D. & Minimum & Maximum & KR20 \\
\hline 159 & 11.9 & 4.7 & 3 & 21 & 0.801 \\
\hline
\end{tabular}

The facility values and point biserials of individual items in all three trials were also examined. However, the present author found no items that are too problematic for the present study and decided to include all items in the factor analytic study.

\subsubsection{Factor analysis}

The full-information factor analysis was applied to all the items in Final Trial. Tables of factor loadings are presented in Table 5. In the factor analytic study of Final Trial, the oblique (PROMAX) analysis was, again, thought to be preferable for its interpretability and because some factors (literal and inferential factors and local and global factors, if they exist) might possess correlational relationship with each other.

A three-factor solution was adopted. The correlations between the first and second factor is 
high (.558), the correlations between the first and third factor and the second and third factor are low (.330 and .251). The reading test taking process of each item that was identified in Study 1 is indicated in Table 5 (via a, b, and c). Furthermore, in Table 6, the count of items from each reading test taking process (identified in Study 1 ) that loaded heavily on each factor is displayed. The items are judged to be loading heavily when the loading is above .40 .

Table 5 Full-information factor analysis (three-factor solution) of Final Trial items

\begin{tabular}{|c|c|c|c|c|c|c|c|c|}
\hline \multicolumn{4}{|c|}{ Final Trial (3 factors) } & & & & & \\
\hline \multicolumn{2}{|c|}{ promax } & 1 & 2 & 3 & & & & \\
\hline c & 20 & .933 & -.433 & -.013 & & & & \\
\hline $\mathbf{a}$ & 17 & .764 & -.363 & -.098 & & & & \\
\hline $\mathrm{b}$ & 2 & .696 & -.178 & -.083 & & & & \\
\hline $\mathrm{b}$ & 19 & .640 & -.135 & .027 & & & & \\
\hline b & 3 & .629 & -.030 & -.009 & & & & \\
\hline$b$ & 12 & .611 & .246 & -.073 & & & & \\
\hline$a$ & 7 & .588 & .154 & .027 & & & & \\
\hline c & 14 & .548 & .374 & .005 & & & & \\
\hline $\mathrm{b}$ & 21 & .452 & .323 & -.368 & & & & \\
\hline $\mathbf{a}$ & 11 & .451 & .274 & -.041 & & & & \\
\hline $\mathrm{b}$ & 1 & .422 & -.022 & .521 & & & & \\
\hline c & 13 & .416 & -.007 & .086 & & & & \\
\hline$b$ & 16 & .405 & .003 & .474 & & & & \\
\hline $\mathbf{a}$ & 4 & .346 & .044 & -.187 & & & & \\
\hline b & 8 & .337 & .423 & -.931 & & & & \\
\hline b & 18 & .255 & .501 & -.123 & & & & \\
\hline c & 15 & .194 & .414 & -.138 & & & & \\
\hline b & 5 & .113 & .186 & .404 & & romax & correl. & \\
\hline$a$ & 22 & .043 & -.242 & -.064 & & 1 & 2 & 3 \\
\hline b & 10 & .016 & .433 & .090 & 1 & 1 & & \\
\hline c & 9 & -.247 & .669 & .191 & 2 & .558 & 1 & \\
\hline$c$ & 6 & -.490 & 1.075 & -.304 & 3 & .330 & .251 & 1 \\
\hline
\end{tabular}

Table 6. Number of items from each reading test taking process that loaded heavily on each factor

\begin{tabular}{|l|c|c|c|}
\hline $\begin{array}{l}\text { Reading Factors from Study 2 } \\
\text { test taking process } \\
\text { perceived in Study 1 }\end{array}$ & F1 & F2 & F3 \\
\hline a. local literal & 3 & 0 & 0 \\
\hline b. local inferential & 7 & 3 & 3 \\
\hline c. global inferential & 3 & 3 & 0 \\
\hline
\end{tabular}

The first thing noticed is that the text (context) characteristics did not affect the extraction of factors. Items from different prompts or passages had significant loadings on the same factors, and the loadings of the items that were allotted to the same prompt or passage varied greatly for each factor. The loadings are generally quite high, even much higher than the loadings in Study 1. 
This shows that, since this is a three-factor solution which was also employed in the three trials in Study 1, the high loadings that the items had on the factors in Study 1 were preserved and even strengthened in the outcome of Study 2. Although a closer study of factors and items are necessary, this could mean that the reading test taking processes identified in Study 1 were valid. Many items loaded quite heavily on the first factor, which could mean that the reading ability measured is unitary. Nevertheless, the result indicates that multidimensionality of the reading ability because three items loaded distinctively heavily on the second factor and two items loaded distinctively heavily on the third factor, suggesting the existence of the second and third element in reading ability.

From Table 6, it is evident that the third factor is, indeed, a 'local inferential factor' because no items from local literal or global inferential reading test taking process loaded heavily on this factor. However, considering the number of 'local inferential' items included in Final Trial (eleven out of 22), it may be not so reliable to conclude that the third factor is 'local inferential' factor just because two 'local inferential' items loaded heavily on the third factor. Nevertheless, one thing that is evident from the factor loadings on the third factor is that there is a significant separation in loadings between the items that had high loadings (items 1,5 and 16) and those that didn't. This means that items 1,5 and 16 was perceived to possess distinct nature from other items.

When the actual test questions are consulted, item 1, 5 and item 16, which bore high loadings on the local inferential factor in Study 1, were the items that were consulted as typical examples of local inferential reading item in interpreting reading test taking processes. Their loadings on the third factor were distinctively high because they were very typical of local inferential reading test taking process. On this account, the interpretation of the third factor as local inferential reading test taking process is further confirmed.

The second factor seems to be the 'global inferential' factor since three items from global inferential factor loaded quite highly on the second factor. When the actual test items were consulted, they were indeed explained as global inferential type. Furthermore, item 6 loaded negatively high on the other two factors, and item 20 and 17, which loaded heavily on the first (local literal) factor, loaded negatively high on the second factor. This, even more, confirms the global and, with less intensity, inferential nature of the second factor. There was no item from 'local literal' reading test taking process that loaded heavily on the second factor. This might further indicate that the second factor is mote on global inferential side.

The first factor is the most difficult one to interpret probably because many items load heavily on it. A paradoxical result of three items from 'local literal' reading test taking process, seven items from 'local inferential' reading test taking process, and three items from 'global inferential' reading test taking process loading heavily on the first factor is displayed in Table 6. Just by looking at the numbers of items, one might wonder why the first factor should be considered to be "local literal" comprehension. However, the test set originally had only five of "local literal" items from Study 1. Therefore, the fact three out of five items loaded heavily on the first factor could be considered as an evidence that the first factor is, indeed, "local literal" 
comprehension factor.

The 'local literal' items that loaded heavily on the first factor in Study 2 are items 17, 7, and 11. Item 11 was a typical 'local literal' item. Items 17 and 7 seemed to be 'local inferential' type ("The word " $\mathrm{X}$ " in line $\mathrm{Y}$ refers to' type) at first, but the answer could be found simply by locating the answer, making them 'local literal' items. Furthermore, what could be noticed about the five 'local inferential' items that loaded heavily on the first factor is that when the actual test questions are inspected, they are all 'local' items with just a slight inference necessary. The degree of inference that is required in these items is perceived to be smaller than that required in the two local inference items that loaded heavily on the third factor (items 1 and 16).

One cannot judge how or by doing what type of reading the testees succeeded in answering the question only from the results of factor analyses. It is possible that, although the reading itself was not successful, the testee could have reached the correct answer anyway. This indicates the possibility, as it was suggested in Negishi (1996), that the testees do not always answer items in the way the test constructor intends them to do. Nevertheless, it is interpreted from the results of factor analysis and the inspection of the test items that the first factor is local literal factor in reading ability.

\subsubsection{Discussion of Study 2}

\subsubsection{Dimensionality of reading ability}

In the factor analytic study of Final Trial, it was perceived that the reading ability is multidimensional. It confirms the multidimensionality that was suggested in the three trials of Study 1. Furthermore, the fact that the items in Study 2 were the items that loaded heavily on one of the three factors in previous trials, and that they still loaded heavily (most of them even heavier) on the factors in Study 2, proves the validity of operationalizing reading ability through perceived reading test taking processes and partly answers Research Question 3, which challenged the validity of the results obtained in Study 1.

However, although the three-factor solution seemed to have worked well in the analysis, it is also true that the factors seemed to present less obviousness. Many of the items loaded heavily on the first factor. This could suggest the unidimensionality of reading ability with the first factor being a 'unitary reading ability'. However, a closer inspection of loadings proved that there is a great separation between those items that load heavily and those that load less heavily on the second or the third factor. This proves the distinct nature of each of the three factors identified in the three-factor solution and hence the tmultidimensionality of reading ability. The patterns of how certain items loaded similarly provided useful insights into defining different reading test taking processes. (See section 4.2.3.2. and 4.2.3.3. for further discussion.) Furthermore, these patterns that explained the reading test taking processes, also validates the multidimensionality of reading ability.

\subsubsection{Dimensions of reading construct}

The fact that the items in Study 2 were the items that loaded heavily on one of the three factors in previous trials and that they still loaded heavily (most of them even heavier) on the same factors in Study 2 lends some insight to the definitions of dimensions that constitute reading 
construct. A table of how the reading test taking process of each item was identified by the factor loadings in Study 1 and Study 2 is provided in Table 7. The reading test taking processes (local literal comprehension, local inferential comprehension, global inferential comprehension) are mostly stable for the items whose reading test taking processes were clearly identified in the factor analysis in Study 2, when the items are tested in a different group of items. This further confirms the validity of interpretations made on the three factors as the three reading test taking processes. Even though the items were given as a different set to a different group of students in Study 2, the three factors that were extracted in three-factor solution were quite similar to the ones that were identified from the three trials of Study 1, hence, a solution to Research Question 3.

Table 7 Reading test taking process of each item identified in Study 1 and Study 2, and stable factor(s) between Study 1 and Study 2

\begin{tabular}{|c|c|c|c|}
\hline Item \# & $\begin{array}{c}\text { Identification from } \\
\text { Study } 1\end{array}$ & $\begin{array}{c}\text { Identification from } \\
\text { Study } 2\end{array}$ & $\begin{array}{c}\text { stable factor(s) } \\
\text { between S1\&S2 }\end{array}$ \\
\hline 1 & $\mathrm{~L} \mathrm{In}$ & $\mathrm{L} \mathrm{In}$ & local inferential \\
\hline 2 & $\mathrm{~L} \mathrm{In}$ & $\mathrm{L} \mathrm{Li}$ & local \\
\hline 3 & $\mathrm{~L} \mathrm{In}$ & $\mathrm{L} \mathrm{Li}$ & local \\
\hline 4 & $\mathrm{~L} \mathrm{Li}$ & - & - \\
\hline 5 & $\mathrm{~L} \mathrm{In}$ & $\mathrm{L} \mathrm{In}$ & local inferential \\
\hline 6 & $\mathrm{G} \mathrm{In}$ & $\mathrm{G} \mathrm{In}$ & global inferential \\
\hline 7 & $\mathrm{~L} \mathrm{Li}$ & $\mathrm{L} \mathrm{Li}$ & local literal \\
\hline 8 & $\mathrm{~L} \mathrm{In}$ & $\mathrm{G} \mathrm{In}$ & inferential \\
\hline 9 & $\mathrm{G} \mathrm{In}$ & $\mathrm{G} \mathrm{In}$ & global inferential \\
\hline 10 & $\mathrm{~L} \mathrm{In}$ & $\mathrm{G} \mathrm{In}$ & inferential \\
\hline 11 & $\mathrm{~L} \mathrm{Li}$ & $\mathrm{L} \mathrm{Li}$ & local literal \\
\hline 12 & $\mathrm{~L} \mathrm{In}$ & $\mathrm{L} \mathrm{Li}$ & local \\
\hline 13 & $\mathrm{G} \mathrm{In}$ & $\mathrm{L} \mathrm{Li}$ & - \\
\hline 14 & $\mathrm{G} \mathrm{In}$ & $\mathrm{L} \mathrm{Li}$ & - \\
\hline 15 & $\mathrm{G} \mathrm{In}$ & $\mathrm{G} \mathrm{In}$ & global inferential \\
\hline 16 & $\mathrm{~L} \mathrm{In}$ & $\mathrm{L} \mathrm{In}$ & local inferential \\
\hline 17 & $\mathrm{~L} \mathrm{Li}$ & $\mathrm{L} \mathrm{Li}$ & local literal \\
\hline 18 & $\mathrm{~L} \mathrm{In}$ & $\mathrm{G} \mathrm{In}$ & inferential \\
\hline 19 & $\mathrm{~L} \mathrm{In}$ & $\mathrm{L} \mathrm{Li}$ & local \\
\hline 20 & $\mathrm{G} \mathrm{In}$ & $\mathrm{L} \mathrm{Li}$ & - \\
\hline 21 & $\mathrm{~L} \mathrm{In}$ & $\mathrm{L} \mathrm{li}$ & local \\
\hline 22 & $\mathrm{~L} \mathrm{Li}$ & - & - \\
\hline & & & \\
\hline
\end{tabular}

\subsubsection{3. 'Two-dimensional' approach to reading construct}

Now that the validity of the three dimensions identified in Study 1 and Study 2 has been discussed, the discussion turns to the validity of two-dimensional approach to the testing of reading. With regard to the 'two-dimensional' approach taken in Figure 2 in the present study, the fourth dimension, 'global literal' dimension, was not identified in Study 2 again. This is not surprising because such dimension was not identified in Study 1, either, and the items in Study 2 were selected from the items in Study 1. Again, the possibilities are: 1) The present reading construct, which is illustrated by 'two-dimensional' plane, is not valid, and some other way to describe reading construct should be sought, 2) No items that elicit the reading test taking process identified 
by the dimension of 'global literal comprehension' were present in the three trials, 3) Although there were items that elicit 'global literal comprehension' in the three trials, students did not do the type of reading intended by such items, or 4) (a sort of synthesis of 2 and 3) failure to include 'time' constraints to reflect both 'power' factor and 'speed' factor of reading. From a paradoxical way of how factor loadings turned out to be for item 8, loading highly on both local literal factor and global inferential factor, 4) described above seems valid. On the other hand, one should remember that TOEIC and TOEFL does not include 'speed' element in their specifications, either, though they include global literal reading process as a subskill to be tested by their items. Further research should be carried out.

One interesting result obtained in Study 2 regarding the dimension of reading test taking processes measured by the present instrumentations was the relationship of the first factor and the second factor. In some cases, the items that loaded heavily on one factor had negatively heavy loadings on another factor. This could mean that one factor, which could be explained by 'global inferential' factor, could be placed on one side of the dimensions and the other factor, which could be explained by 'local literal' factor, could be placed on the other end of the same plane (See Figure 3a). Furthermore, the fact that the third factor was present with distinctly high loadings indicates that there, indeed, is the third dimension (See Figure 3b). Moreover, as it was discussed in the beginning of this section, there is a high possibility that there exists the fourth dimension, 'global literal dimension', if a right methodology is taken in the research (See Figure 3c).

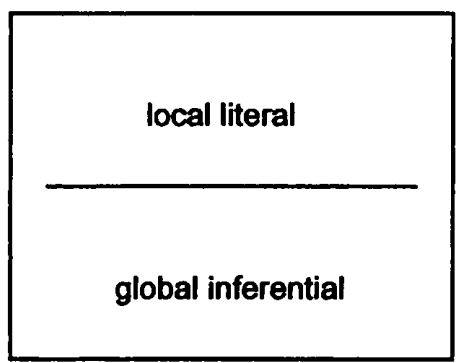

Figure 3a

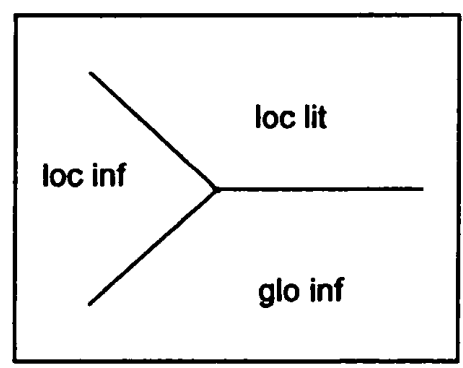

Figure 3b

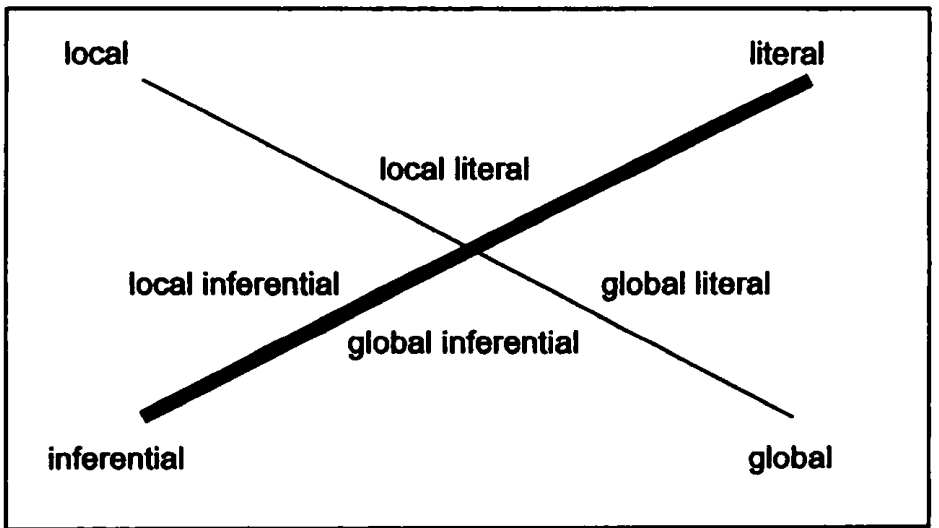

Figure 3c

Figure 3. The reading subskills models after factor analytic study of Study 2 
When a model like Figure $3 \mathrm{c}$ is suggested, a common skepticism made against it is whether the ends of axes are empirically found to be on 'opposite' ends of the axes. In the present study, it was interpreted from the factor analytic study that literal factor and inferential factor could indeed be placed on the opposite ends. The same is true for the local factor and the global factor.

It is fundamentally difficult to draw a decisive line to categorize the reading test taking processes because reading is an integrative activity. For instance, items 1, 12, 16, and 19 were the items that were categorized as local inferential items in Study 1. However, in the factor analytic studies of Study 2, items 1 and 16 were categorized as local inferential items, and items 12 and 19 were categorized as local literal items. Indeed, the amount of inferring necessary for items 1 and 16 is greater than that of items 12 and 19 , and this did not have much influence on the factor analytic study of Study 1, but it did on that of Study 2. This indicates the continuity of the literal comprehension dimension and the inferential comprehension dimension. The concept of cognitive 'continuity' in reading ability between the local-global dimension and the literal-inferential dimension was discussed in section 2.2., and it was also confirmed in the present study.

On the other hand, the interface between the global dimension and the local dimension was more decisive in the present study. Items 18 and 20 were the only items in which there was a shift in local-global dimension (See Table 7). Therefore, in order to indicate the difference in the intensity of continuity between the local end and global end and the literal end and inferential end on axes, the axes are different in their thickness in Figure 3c. The local-global axis is thinner than the literal-inferential axis because items tend to shift their types between the literal dimension and the inferential dimension much more freely than it does between the local dimension and the global dimension. This difference in the intensity of continuity is true only in the local side and not confirmed for the global side of Figure $3 \mathrm{c}$ since global literal factor was not present in the present study. This should be investigated in a further study with a more appropriate methodology.

The area of each dimension indicates the continuity of dimensions that ate next to each other, although this, too, demand for a further investigation. In Study 2 (Table 5), there was a large separation of items that loaded heavily on the first factor (local literal) and those on the second factor(global inferential). This suggests that reading test items tend to elicit these two types of reading processes very often. Furthermore, the fact that many of the items which were identified as 'local inferential' items in Study 1 loaded heavily on either the local literal factor or the global inferential factor might be suggesting that local inferential factor is rather unstable compared to the other two. This could mean that the local aspect and the literal aspect of reading, which make up local literal reading test taking process, are closer in human cognitive process. The same might be true for the global aspect and the inferential aspect of reading, which make up global inferential reading test taking process. Therefore, the present author decided to illustrate the cognitive closeness of global and inferential dimensions and local and literal dimensions via the size of area each reading test taking processes are allotted. 


\section{CONCLUSION}

The present research suggests that the reading ability measured via performance of senior high school students in Japan on L2 reading comprehension tests is multidimensional. The L2 reading ability measured by TOEFL and TOEIC reading tests include at least three reading test taking processes: local literal, local inferential, and global inferential. Possibly, the fourth type, global literal, which was suggested in Negishi (1997) but was not found in the present study, may be existent if a more appropriate methodology was taken in the research. Although the fourth reading test taking process was not present in the present study, the factor analytic studies showed that it is valid to describe reading construct measured via TOEFL and TOEIC reading tests in two-dimensional approach as in Figure 3c. The continuity of two ends on the axes (local-global and literal-inferential), decisiveness of the local-global dimension being stronger than that of the literal-inferential dimension, and the cognitive closeness of local-literal aspect and global-inferential aspect are some unique and original notions at which the present study arrived.

Test specifications account for how the test constructors define reading ability. Without clear and valid test specifications, it is impossible to tell what the test is measuring, and therefore, the test has no value in itself. The present study sought for a way to define reading ability by breaking it down into smaller components through factor analytic studies of how learners perform on standardized TOEFL and TOEIC items. An idea of 'reading ability' framed by two axes that represent the quantity of information processed and the quality of processing necessary would help constructors of reading tests to focus on what type of reading ability (i.e. local literal, local inferential, global inferential) they want to elicit by the test item. The present study attempted to illustrate reading construct in the two-dimensional model of what test taking reading process test items elicit. It is hoped that the outcome of the present research be of some use to the future test construction.

\section{ACKNOWLEDGEMENTS}

This paper is based on the author's MA thesis submitted to Tokyo University of Foreign Studies. She would like to thank Prof. NEGISHI Masashi for his guidance, Prof. TAJIMA Nobumoto for his constructive advice, and Mr. Paul ROBERTS for reviewing earlier versions of this paper.

\section{NOTES}

1. \& 2. The present author was not able to compile the test instruments employed in the present study in this paper because of the page limitation.

\section{REFERENCES}

Alderson, J. C. 1990. "Testing reading comprehension skills (Part 1)." Reading in a Foreign Language, 6(2): 425-438.

Alderson, J. C., and Lukmani. Y. 1989. "Cognition and reading: cognitive levels as embodied in test questions." Reading in a Foreign Language, 5(2): 253-270. 
Bernhardt, E. 1999. "If reading is reader-based, can there be a computer-adaptive test of reading?" In Chalhoub-Deville, M. (Ed.), pp.1-10.

Blais, J. and Laurier, M.D. 1995: "The dimensionality of a placement test from several analytical perspectives." Language Testing 12(1): 72-98.

Chalhoub-Deville, M. 1999. Issues in computer-adaptive testing of reading proficiency, Cambridge: Cambridge University Press.

Gernbacher, M.A. 1990. Language comprehension as structure building. Hillsdale, NJ: Lawrence Erlbaum Associates Publishers.

Grabe, W., 1999. "Developments in reading research and their implications for computer-adaptive reading assessment." In Chalhoub-Deville, M. (Ed.) pp.11-47.

Henning, G. 1992. "Dimensionality and construct validity of language tests." Language Testing, 9(1): 1-11.

Lumley, T. 1993. "The notion of subskills in reading comprehension tests: an EAP example." Language Testing, 10(3): 211-235.

Lumley, T. 1995. "Responses and replies: Tom Lumely replies." Language Testing, 12(1): 125-130

Negishi, M. 1996. The latent trait structure of $L 2$ reading comprehension tests. Unpublished $\mathrm{PhD}$ thesis, Center for Applied Language Studies, University of Reading.

Negishi, M. 1997. "Yomi-no-chikara-wo-dou-hyouka-suru?" in ALC Press (Ed.) Eigo-Kyouiku-Jiten (pp.44-49). Tokyo: ALC Press.

Rost, D.H. 1993. "Assessing different components of reading comprehension: fact or fiction?" Language Testing 10(1): 79-92.

Shizuka, T. 1998. "Unidimensionality of reading ability and working memory capacity: implications for L2 reading tests." Tokyo Gakugei Daigaku Kiyou: 65-78.

Shizuka, T. 1999. "Two -dimensional classification of reading test items." JLTA Journal 2: 85-104.

Urquhart, S. and Weir, C. 1998. Reading in a foreign language: process, prodict and practice.

London: Longman. 